\title{
Enhancement of the Marginal Area in Colorectal Cancer Liver Metastasis on Computed Tomography Correlates With Microvessel Density and Clinicopathological Factors
}

\author{
YUKI YANO, KAZUHIKO YOSHIMATSU, HAJIME YOKOMIZO, \\ MASANO SAGAWA, HIROKO ITAGAKI and YOSHIHIKO NARITAKA
}

\author{
Department of Surgery, Tokyo Women's Medical University Medical Center East, Tokyo, Japan
}

\begin{abstract}
Background: Previously, we aimed to predict the effect of bevacizumab in liver metastasis using the ratio of the computed tomography $(C T)$ value for hepatic metastatic lesions in the arterial phase in contrast-enhanced (CE) CT to that on plain CT. However, there is no report on the relation between the CT contrast effect and microvessel density (MVD) in liver metastasis. Patients and Methods: Thirty-two patients who underwent liver resection for metastasis from colorectal cancer (excluding neoadjuvant chemotherapy cases) between April 2006 and October 2011 at our Department were analyzed retrospectively. The relation between the CE ratios obtained from the whole tumor or tumor margin and the MVD using the liver metastatic lesion of colorectal cancer were analyzed. It was also examined whether the CE ratios and MVD were related to the clinicopathological factors of the primary tumor. Results: There was a significant correlation between the CE ratios obtained from assessment using the entire tumor and the tumor margin as regions of interest (ROI). Furthermore, there was a significant correlation between the MVD and CE ratios. Cases with lymphatic invasion, N2, N3 nodal status and grade $B$ and $C$ were significantly more often observed in the group with high MVD. In contrast, in the group with high CE using the whole tumor as ROI, cases with grade $B$ or $C$ were significantly fewer. However, the number of hepatic metastasis was significantly higher and the diameter was significantly larger in the group with high CE using the tumor margin as ROI. Moreover, cases with grade $B$ or $C$ were recognized significantly more often. Conclusion: The $C E$ ratio correlated
\end{abstract}

This article is freely accessible online.

Correspondence to: Kazuhiko Yoshimatsu, 2-1-10 Nishiogu, Arakawa-ku, Tokyo, Japan. Tel: +81 338101111, Fax: +81 338945493, e-mail: kyoshsu@twmu.ac.jp

Key Words: Contrast enhanced computed tomography, colorectal cancer, liver metastasis. with the MVD. The CE ratio using the tumor margin was similar to the MVD in relation to the clinicopathological factors. Taken together, these findings suggest that the CE ratio using the tumor margin as ROI may reflect MVD.

In colorectal cancer, liver metastasis exists in approximately $10 \%$ of cases at initial diagnosis. Additionally, liver metastasis is the most frequently recognized as the first metastatic site after curative resection (1). In order to improve the outcome of patients with advanced colorectal cancer, it is important to control hepatic metastasis. Because curative resection of liver metastasis can lead to disease cure, surgical treatment is desirable for resectable cases (2). Since chemotherapy for metastatic colorectal cancer has progressed in recent years, conversion therapy, a widely held concept for liver metastasis in patients initially evaluated as unresectable which changes to resectable after response to chemotherapy, has been reported to improve the prognosis of patients with colorectal cancer liver metastasis $(3,4)$.

Since antibodies to epidermal growth factor receptor (EGFR) have the effect of early tumor shrinkage, they are often used in anticipation of conversion therapy (5-8). However, Kirsten rat sarcoma viral oncogene (KRAS)-mutated tumor cases cannot be treated with anti-EGFR. On the other hand, there are few contraindications to treat such cases with bevacizumab, an anti-vascular endothelial growth factor (VEGF) drug. We previously studied the effect of bevacizumab on liver metastasis using the ratio of the computed tomography (CT) value for hepatic metastatic lesions in the arterial phase in contrast-enhanced (CE) CT to that on plain CT (9). In cases with a high $\mathrm{CE}$ ratio, the tumor shrinkage rate was higher, whereas in those with a low CE ratio, no significant difference was noted in the tumor shrinkage rate. In addition, since the CE ratio was attenuated after treatment with bevacizumab, there was the possibility that suppression of neovascularization of the metastatic lesion by bevacizumab might reduce blood flow (9). It can be suggested that the contrast effect in liver metastatic lesions of colon cancer reflects the blood flow, 
however, there is no report investigating the relation between the CT contrast effect and microvessel density (MVD) in liver metastasis. Concerning the MVD, it is reported that the MVD of the primary and metastatic sites was a factor predictive of metastasis and survival $(10,11)$.

In this study, the $\mathrm{CE}$ ratio was evaluated by two methods using the whole area of the metastasis or the lesion's margin in the preoperative CT. We analyzed the relation between the $\mathrm{CE}$ ratio and the MVD using the liver metastatic lesion of colorectal cancer, and examined whether the CE ratio and the MVD are related to clinicopathological factors of the primary tumor.

\section{Patients and Methods}

Patients. Thirty-two patients who underwent liver resection for metastasis from colorectal cancer excluding neoadjuvant chemotherapy cases between April 2006 and October 2011 at our Department were analyzed retrospectively.

CT imaging. CT scan was performed within 1 month before surgery for liver metastasis using a 64- or 16-row multidetector CT scanner (GE Healthcare Ltd, Hino, Japan.). CT scan was performed without contrast medium at first, followed by contrast-enhanced CT scanning during the late arterial phase (40 s) following intravenous injection with a nonionic contrast medium at $600 \mathrm{mgI} / \mathrm{kg}$. Scanning parameters included $5 \mathrm{~mm}$ section thickness, a pitch of 1.375:1, and $120 \mathrm{kV}$ using the Auto-mA feature.

Imaging analysis. Using the imaging control system (INFINITYPACKS; INFINITT JAPAN Co. Ltd. Tokyo, Japan), the largest hepatic metastatic lesion was measured in each patient. The mean CT values using the lesion margin and the whole metastatic lesion were automatically evaluated. Contrast enhancement of the tumors was evaluated in terms of the ratio of the CT value during the late arterial phase to that on the plain CT (i.e. the CE ratio).

For the evaluation using the metastasis margin, the region of interest (ROI) was set at the same peripheral portion of the metastasis in both the late arterial phase and the plain CT. The mean $\mathrm{CE}$ ratio of the marginal area was obtained from three ROIs of metastasis from each patient (Figure 1). For the evaluation of the whole metastatic lesion, the outer edge of the metastatic lesion was delineated using a freehand tool on a monitor (Figure 2). The average $\mathrm{CE}$ values obtained from three independent investigators were used in the analysis.

Immunohistochemical analysis for MVD. Immunohistochemical analysis for MVD was carried out using an autostainer (Ventana Medical Systems Inc., Tucson, AZ, USA). Sections $(4 \mu \mathrm{m})$ of formalin-embedded specimen of the liver metastasis were incubated with mouse anti CD31 (1:20; Dako, Glostrup, Denmark) antibody. Reaction with anti-CD31 was visualized using horseradish peroxidase conjugated secondary antibody and I-VIEW DAB Universal kit (Ventana Medical Systems, Inc.), followed by counterstaining with Carrazzi's hematoxylin solution for $1 \mathrm{~min}$

Five sites of the tumor stroma of the metastasis were randomly selected. The number of microvessels stained with anti-CD30 (12, 13) was counted in a field of view at $400 \times$ and the median value was taken as the MVD (Figure 3). Since the median MVD was 13, values larger than 13 were classified as the high MVD group and values smaller than 13 were classified as the low MVD group.

Statistical analysis. JMP ver. 12.2.0 (SAS institute Inc., Cary, NC, USA) was used for statistical analysis. The correlation between two variables was evaluated using chi-square test and simple linear regression analysis. A statistically significant difference was considered at $p<0.05$.

The protocol of this study was approved by the Institutional Review Board of Tokyo Women's Medical University (approval no. 4659).

\section{Results}

Patient characteristics. The characteristics of the enrolled patients are summarized in Table I. The median age was 70 (range $=33-85$ ) years and there were 22 males and 10 females.

Assessment of CE ratio. CE ratios obtained from assessing the entire metastasis and ROI of the metastasis margin were significantly correlated by simple linear regression analysis (R2=0.4461, $p<0.0001)$ (Figure 4).

MVD and method for determining the CE ratio. The MVD and the $\mathrm{CE}$ ratio obtained from assessing the entire metastasis were significantly correlated $\left(\mathrm{R}^{2}=0.1539\right.$, $p<0.001)$. Additionally, the MVD and the CE ratio obtained from using ROIs of the metastasis margin were significantly correlated $(\mathrm{R} 2=0.1491, p<0.001)$ (Figure 5).

Correlation of MVD with clinicopathological findings. There were no significant differences regarding gender, age, location of primary lesion, type of histology and T-category in relation to MVD. Additionally, there was no significant difference regarding extrahepatic metastasis, timing of hepatic metastasis, number of hepatic metastases and the degree of hepatic metastasis. Cases with lymphatic invasion and N2/N3 nodal status were significantly more often observed in the group with high MVD. There was also a trend for more cases with venous invasion in the group with high MVD. The maximum diameter tended to be larger in the group with high MVD, and cases with grade B or C were significantly more frequent (Table II).

Correlation of CE ratio based on the entire tumor and clinicopathological findings. When patients were divided by the median value into high $\mathrm{CE}$ and low $\mathrm{CE}$ groups, there was no significant difference regarding gender, age, location of primary lesion, type of histology, T-category, lymphatic invasion, venous invasion and nodal status. There was also no significant difference regarding extrahepatic metastasis, timing of hepatic metastasis, and the degree of hepatic metastasis. In the group with high $\mathrm{CE}$, there were significantly fewer cases with grade B or C. Additionally, the 


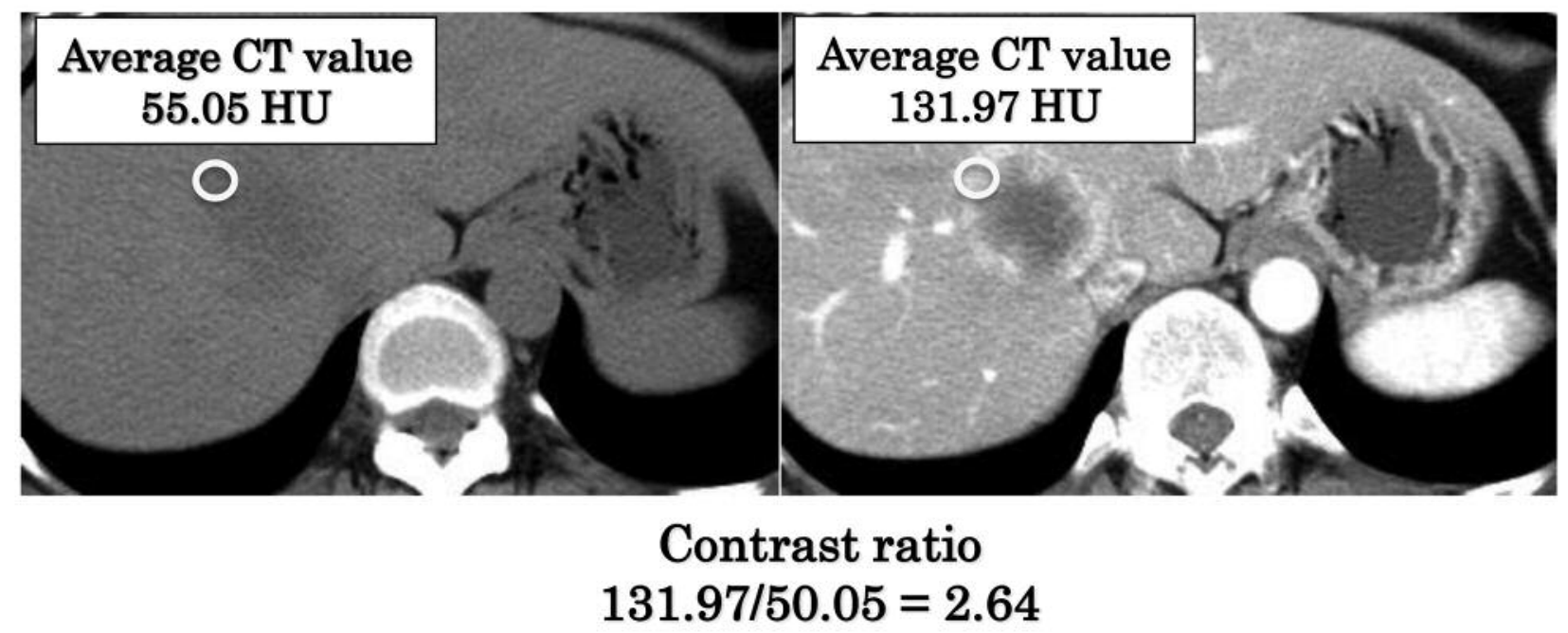

Figure 1. For the evaluation of the marginal area of the metastasis, regions of interest (ROIs) were set at the same peripheral portion of the metastasis in both the late arterial phase and the plain computed tomography (CT). The mean CT ratio of the marginal area was obtained using three ROIs of metastasis from each patient.

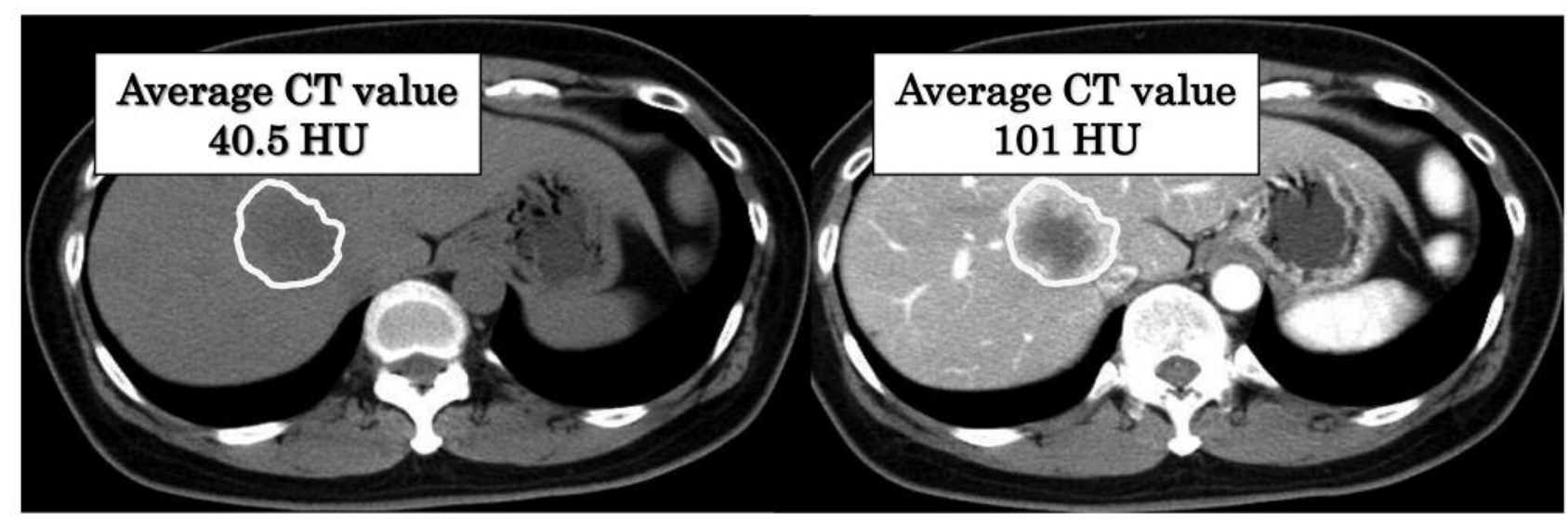

\section{Contrast ratio}

\section{$101 / 40.5=2.49$}

Figure 2. For the evaluation of the whole metastatic lesion by computed tomography (CT), the outer edge of the metastatic lesion was surrounded using a freehand tool on a monitor.

number of hepatic metastases was significantly higher in the group with high CE and the diameter tended to be larger $(p=0.0799)$; cases with metastasis diameter of $25 \mathrm{~mm}$ or more were more frequent, and cases with grade $\mathrm{B}$ or $\mathrm{C}$ tended to be more frequent (Table III).

Correlation of CE ratio based on the tumor margin with clinicopathological findings. When the $\mathrm{CE}$ ratio was divided by the median value into high $\mathrm{CE}$ and low $\mathrm{CE}$ groups, there was no significant difference regarding gender, age, location of the primary lesion, type of histology, T-category, lymphatic invasion, venous invasion, node status, extrahepatic metastasis, timing of hepatic metastasis and the degree of hepatic metastasis. The number of hepatic metastases was significantly higher in the high $\mathrm{CE}$ group and the diameter was significantly larger; cases with grade B or C were significantly more frequent (Table IV). 


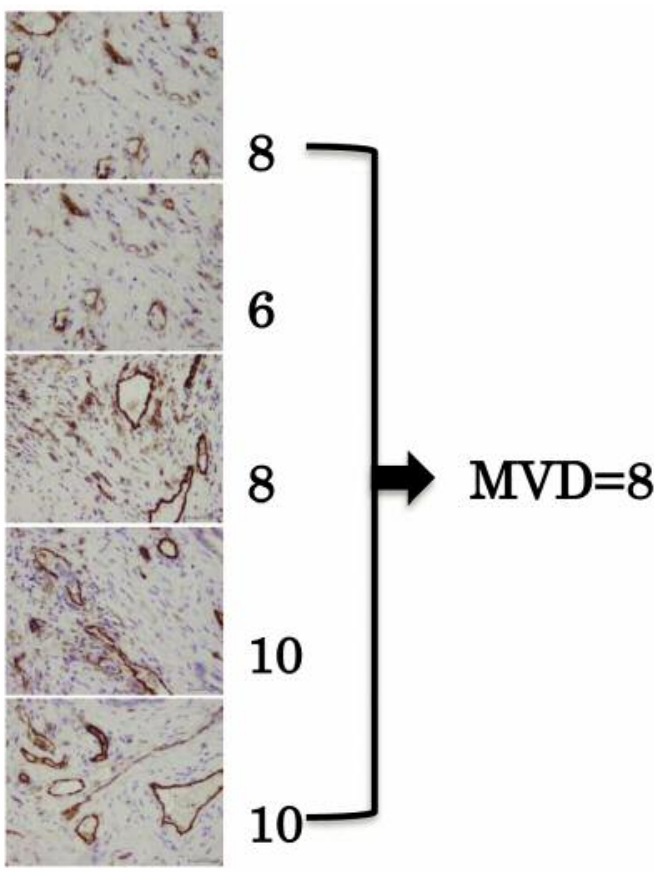

(Low MVD)

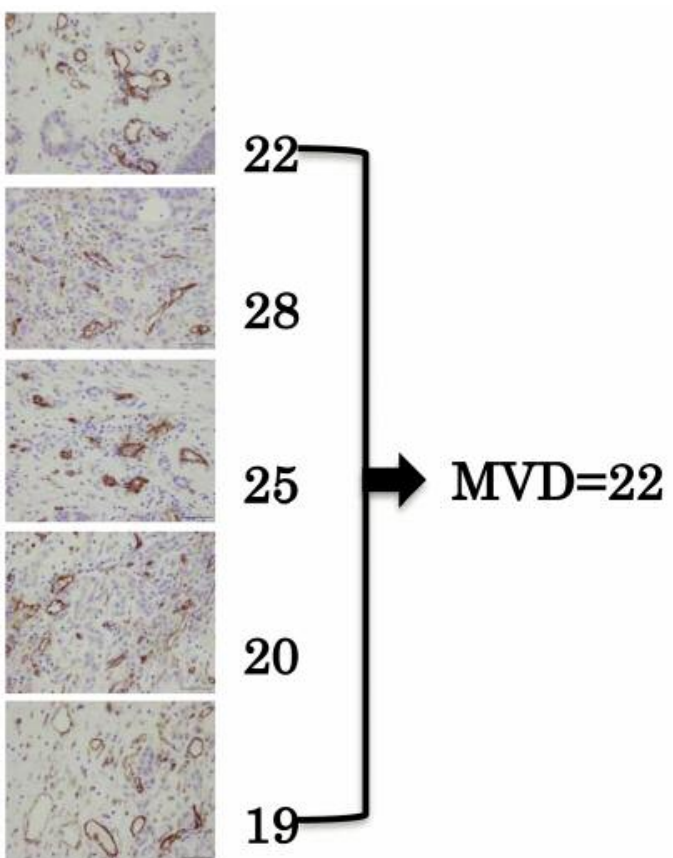

(High MVD)

Figure 3. Tumor stroma of the metastasis was randomly selected from five sites. The number of microvessels stained with anti-CD 31 was counted in a field of view at $400 \times$ and the median value was taken as the microvessel density (MVD).

\section{Discussion}

Specific binding of bevacizumab to human VEGF inhibits binding of VEGF to VEGF receptor on vascular endothelial cells (15-17). During progression and proliferation of tumor in vivo, especially colon cancer cases, VEGF production is known to be enhanced following the increase of neovascularization. Inhibiting the bioactivity of VEGF by bevacizumab inhibits tumor growth via inhibition of angiogenesis or normalization of the immature and incomplete blood vessels induced by VEGF from tumors (17-20). During chemotherapy combined with bevacizumab for patients with colorectal cancer patients, liver metastatic lesions often show a cystic change in the CT image which indicates an antitumor effect without shrinkage. Patients with complete cystic changes are reported to have a favorable prognosis (22). These findings support the fact that tumor necrosis is induced by the blockade of blood flow by bevacizumab. Our previous report indicated that the $\mathrm{CE}$ ratio in the metastatic lesion in the liver decreased after chemotherapy induction combined with bevacizumab in patients with colon cancer liver metastasis (9). This observation also suggested that a decrease of CE ratio in the liver metastatic lesion indicates reduced blood flow in the tumor area due to inhibition of angiogenesis by bevacizumab

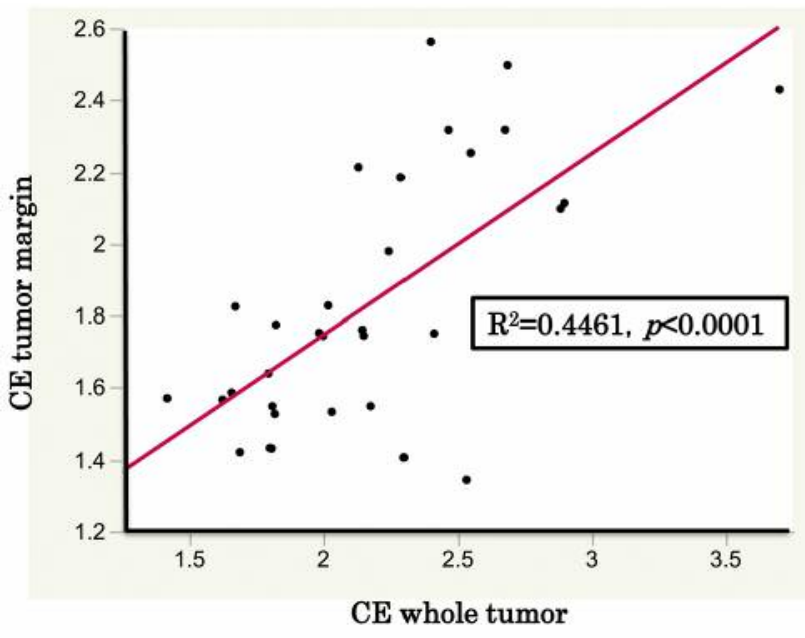

Figure 4. Correlation of contrast enhancement (CE) ratios obtained from assessment using the whole tumor and tumor margin as regions of interest.

induced in the tumor cells. Therefore, this study was conducted to investigate the correlation between the CT contrast effect and MVD using the cases which underwent resection of liver metastases. 

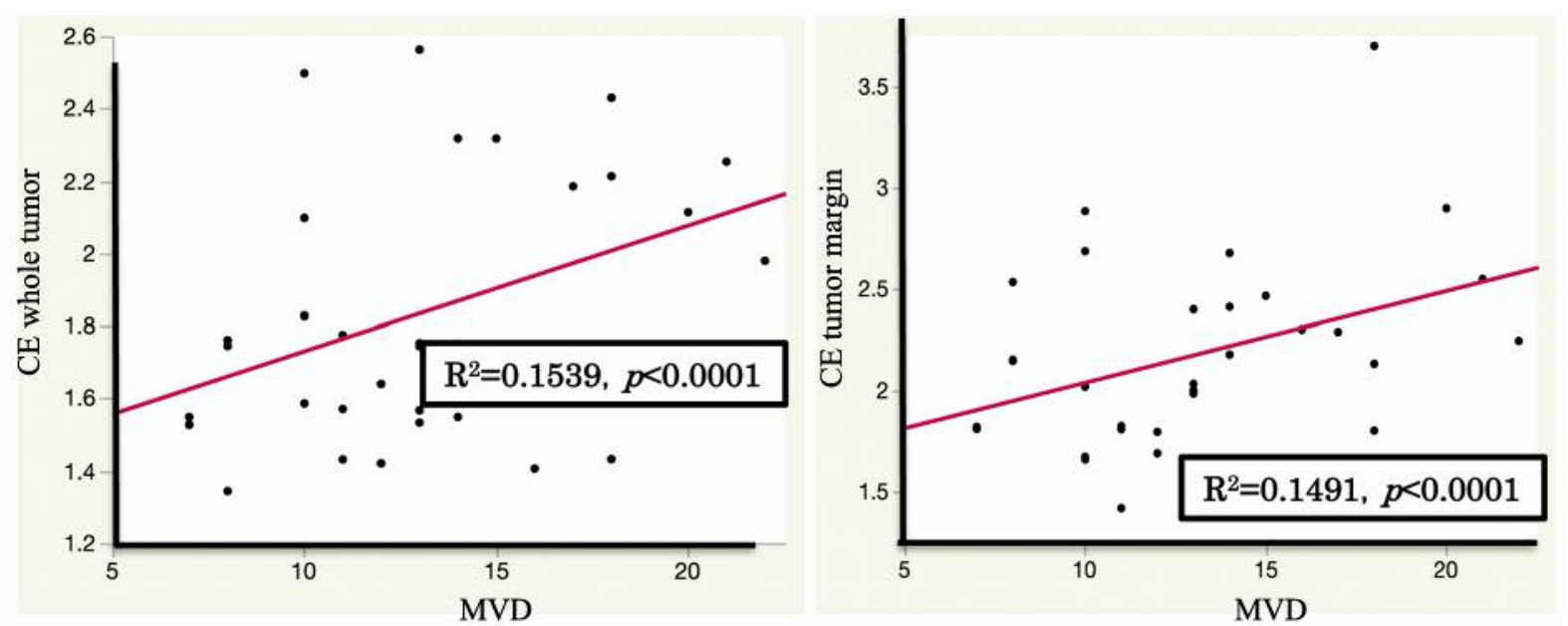

Figure 5. Correlation of microvessel density (MVD) and contrast enhancement (CE) ratios obtained from assessment using the whole tumor and tumor margin as regions of interest.

Table I. Patient background characteristics.

\begin{tabular}{ll}
\hline Characteristic & Value \\
\hline Age, years & \\
$\quad$ Median (range) & $70(33-85)$ \\
Gender, $\mathrm{n}$ & 22 \\
$\quad$ Male & 10 \\
Female & \\
Site of disease, $\mathrm{n}$ & 26 \\
Colon & 6 \\
Rectum & $25.2(13-94.6)$ \\
Size of metastasis, mm & \\
Median (range) & 28 \\
Degree, $\mathrm{n} *$ & 2 \\
H1 & 2 \\
H2 & \\
H3 & 21 \\
Grade, $\mathrm{n} *$ & 7 \\
A & 4 \\
B & \\
C & 15 \\
Timing of hepatic metastasis, $\mathrm{n}$ & 17 \\
Synchronous & \\
Metachronous &
\end{tabular}

*According to Japanese Classification of Colorectal Carcinoma (14).

FirstIy, when the evaluation of CE ratio using the marginal region or the whole metastatic lesion was carried out, a significantly positive correlation was found between the evaluation methods. Additionally, for both methods, the CE ratio significantly positively correlated with MVD in the metastatic lesion. Taken together, it could be considered that the effect of the CT contrast enhancement reflects the blood vessel density of the tumor. In other words, if the high contrast effect represents a high MVD induced by VEGF, the efficacy of bevacizumab against a metastatic lesion with high CE might be predicted.

Generally, primary lesions associated with high MVD or high VEGF tend to metastasize, and there tends to be similar characteristics in the metastatic lesion $(10,11)$. In this study, the relation between MVD, CT contrast enhancement and clinocopathological factors were investigated. In the group with high MVD for the liver metastatic lesion, cases with lymphatic invasion and venous invasion of the primary site were significantly more than frequent than in the low MVD cases. There tended to be more lymph node-positive cases found in those with high MVD. In addition, cases with larger metastatic tumor diameters and more metastatic nodules had higher MVD in their metastatic lesions. These findings were also shown in the cases with $\mathrm{CE}$ ratio evaluated using the marginal region. However, the relation was dissimilar in the cases with $\mathrm{CE}$ ratio evaluated using the whole metastatic tumor. Although the $\mathrm{CE}$ ratio correlated with the MVD regardless of whether it was evaluated using the margin or the whole metastatic lesion, the evaluation of contrast enhancement at the margin might be better than that of the whole metastatic lesion in the prediction of the MVD based on the compatibility with the clinicopathological factors. This might be explained by the fact that compared with using the lesion margin, evaluating an entire metastasis includes a wide area of necrosis, which may disproportionally affect the evaluation of MVD.

Konerding et al. reported that the intervessel distance was shorter in primary colorectal tumors which had already metastasized with compared to those without metastases at the time of surgery (22). In other words, the MVD was high in primary tumors with metastasis. If the MVD is higher in 
Table II. Clinicopathological factors according to microvessel density (MVD).

\begin{tabular}{|c|c|c|c|}
\hline Factor & $\begin{array}{l}\text { High } \\
\text { MVD }\end{array}$ & $\begin{array}{l}\text { Low } \\
\text { MVD }\end{array}$ & $p$-Value \\
\hline \multicolumn{4}{|l|}{ Gender, $\mathrm{n}$} \\
\hline Male & 11 & 11 & \multirow[t]{2}{*}{0.712} \\
\hline Female & 6 & 4 & \\
\hline \multicolumn{4}{|l|}{ Age, years } \\
\hline Median (range) & $70(33-82)$ & $70(36-85)$ & 0.5969 \\
\hline \multicolumn{4}{|l|}{ Site of disease } \\
\hline Colon & 14 & 12 & \multirow[t]{2}{*}{0.9999} \\
\hline Rectum & 3 & 3 & \\
\hline \multicolumn{4}{|l|}{ Differentiation, $\mathrm{n}$} \\
\hline Well, moderate & 16 & 14 & \multirow[t]{2}{*}{0.4839} \\
\hline Poorly, mucinous & 0 & 1 & \\
\hline \multicolumn{4}{|l|}{ Tumor depth, $\mathrm{n}$} \\
\hline $\mathrm{T} 3$ & 12 & 14 & \multirow[t]{2}{*}{0.3326} \\
\hline $\mathrm{T} 4$ & 4 & 1 & \\
\hline \multicolumn{4}{|c|}{ Lymphatic invasion, $\mathrm{n}$} \\
\hline Positive & 11 & 4 & \multirow[t]{2}{*}{0.0106} \\
\hline Negative & 4 & 11 & \\
\hline \multicolumn{4}{|l|}{ Venous invasion, $\mathrm{n}$} \\
\hline Positive & 9 & 4 & \multirow[t]{2}{*}{0.0654} \\
\hline Negative & 6 & 11 & \\
\hline \multicolumn{4}{|l|}{ Nodal status, $\mathrm{n}$} \\
\hline N0, N1 & 10 & 14 & \multirow[t]{2}{*}{0.0402} \\
\hline $\mathrm{N} 2, \mathrm{~N} 3$ & 6 & 1 & \\
\hline \multicolumn{4}{|c|}{ Extrahepatic metastasis, $\mathrm{n}$} \\
\hline Positive & 2 & 3 & \multirow[t]{2}{*}{0.6454} \\
\hline Negative & 15 & 12 & \\
\hline \multicolumn{4}{|c|}{ Timing of hepatic metastasis, $\mathrm{n}$} \\
\hline Simultaneous & 9 & 6 & \multirow[t]{2}{*}{0.7061} \\
\hline Metachronous & 8 & 9 & \\
\hline \multicolumn{4}{|c|}{ Number of hepatic metastases, $n$} \\
\hline Single & 11 & 12 & \multirow[t]{2}{*}{0.444} \\
\hline Multiple & 6 & 3 & \\
\hline \multicolumn{4}{|c|}{ Size of metastasis, $\mathrm{mm}$} \\
\hline Median & 29.5 & 21 & 0.0813 \\
\hline$\geq 25 \mathrm{~mm}$ & 11 & 6 & \multirow{2}{*}{0.2971} \\
\hline$<25 \mathrm{~mm}$ & 6 & 9 & \\
\hline \multicolumn{4}{|l|}{ Degree, $\mathrm{n}^{*}$} \\
\hline$\geq \mathrm{H} 1$ & 14 & 14 & \multirow[t]{2}{*}{0.6029} \\
\hline$>\mathrm{H} 2$ & 3 & 1 & \\
\hline \multicolumn{4}{|c|}{ Grade of liver metastasis, $\mathrm{n}^{*}$} \\
\hline A & 8 & 13 & 0.0186 \\
\hline $\mathrm{B}, \mathrm{C}$ & 9 & 2 & \\
\hline
\end{tabular}

*According to Japanese Classification of Colorectal Carcinoma (14) Values shown in bold are significantly different $(p<0.05)$.

a metastasis, the prediction of the effect of bevacizumab on metastatic tumor might be judged by the degree of CT contrast enhancement. Strohmeyer et al. also reported that the expression of VEGF and MET proto-oncogene receptor tyrosine kinase (MET) in prostate cancer mainly affected the progression of tumor through an effect on MVD (23). This report suggested that a similar result can be obtained, not only in colon cancer, but also in other cancer types.
Table III. Clinicopathological factors according to the contrast enhancement ratio $(C E)$ based on evaluation of whole metastases.

\begin{tabular}{|c|c|c|c|}
\hline Factor & $\begin{array}{l}\text { High } \\
\text { CE }\end{array}$ & $\begin{array}{l}\text { Low } \\
\text { CE }\end{array}$ & $p$-Value \\
\hline \multicolumn{4}{|l|}{ Gender } \\
\hline Male & 11 & 11 & 0.712 \\
\hline Female & 6 & 4 & \\
\hline \multicolumn{4}{|l|}{ Age, years } \\
\hline Median (range) & $70(33-85)$ & $70(36-82)$ & 0.8205 \\
\hline \multicolumn{4}{|l|}{ Site of disease } \\
\hline Colon & 15 & 11 & 0.3828 \\
\hline Rectum & 2 & 4 & \\
\hline \multicolumn{4}{|l|}{ Differentiation, $\mathrm{n}$} \\
\hline Well, moderate & 17 & 13 & 0.4516 \\
\hline Poorly, mucinous & 0 & 1 & \\
\hline \multicolumn{4}{|l|}{ Tumor depth, $\mathrm{n}$} \\
\hline $\mathrm{T} 3$ & 14 & 12 & 0.9999 \\
\hline $\mathrm{T} 4$ & 3 & 2 & \\
\hline \multicolumn{4}{|c|}{ Lymphatic invasion, $\mathrm{n}$} \\
\hline Positive & 8 & 7 & 0.9999 \\
\hline Negative & 9 & 6 & \\
\hline \multicolumn{4}{|l|}{ Venous invasion, $\mathrm{n}$} \\
\hline Positive & 9 & 4 & 0.2828 \\
\hline Negative & 8 & 9 & \\
\hline \multicolumn{4}{|l|}{ Nodal status, $\mathrm{n}$} \\
\hline N0, N1 & 12 & 12 & 0.4117 \\
\hline $\mathrm{N} 2, \mathrm{~N} 3$ & 5 & 2 & \\
\hline \multicolumn{4}{|c|}{ Extrahepatic metastasis, $n$} \\
\hline Positive & 1 & 4 & 0.1609 \\
\hline Negative & 16 & 11 & \\
\hline \multicolumn{4}{|c|}{ Timing of hepatic metastasis, $n$} \\
\hline Simultaneous & 8 & 9 & 0.7061 \\
\hline Metachronous & 9 & 6 & \\
\hline \multicolumn{4}{|c|}{ Number of hepatic metastases, $n$} \\
\hline Single & 11 & 12 & 0.4440 \\
\hline Multiple & 6 & 3 & 0.2956 \\
\hline \multicolumn{4}{|c|}{ Size of metastasis, $\mathrm{mm}$} \\
\hline Median & 29.1 & 20.4 & \\
\hline$\geq 25 \mathrm{~mm}$ & 11 & 6 & 0.2971 \\
\hline$<25 \mathrm{~mm}$ & 6 & 9 & \\
\hline \multicolumn{4}{|l|}{ Degree, $\mathrm{n}^{*}$} \\
\hline$\geq \mathrm{H} 1$ & 17 & 11 & 0.1571 \\
\hline$>\mathrm{H} 2$ & 0 & 4 & \\
\hline \multicolumn{4}{|c|}{ Grade of liver metastasis, $\mathrm{n}^{*}$} \\
\hline A & 12 & 9 & 0.0186 \\
\hline $\mathrm{B}, \mathrm{C}$ & 5 & 6 & \\
\hline
\end{tabular}

*According to Japanese Classification of Colorectal Carcinoma (14). Values shown in bold are significantly different $(p<0.05)$.

The recent development of dual energy CT has been reported to capture images using different voltages and evaluate the MVD at the target region using the assessment of iodine uptake (24-26). The use of dual energy CT might be able to evaluate the blood flow of liver metastasis from colorectal cancer more precisely than single-energy CT. Future studies utilizing an analysis similar to our report will be needed concerning the methods of MVD assessment, 
Table IV. Clinicopathological factors to the contrast enhancement ratio (CE) based on evaluation of the marginal region.

\begin{tabular}{|c|c|c|c|}
\hline Factor & $\begin{array}{l}\text { High } \\
\text { CE }\end{array}$ & $\begin{array}{l}\text { Low } \\
\text { CE }\end{array}$ & $p$-Value \\
\hline \multicolumn{4}{|l|}{ Gender } \\
\hline Male & 11 & 11 & \multirow[t]{2}{*}{$>0.99$} \\
\hline Female & 5 & 5 & \\
\hline \multicolumn{4}{|l|}{ Age, years } \\
\hline Median (range) & \multicolumn{2}{|c|}{$73(33-85) 68.5(36-82)$} & 0.2954 \\
\hline \multicolumn{4}{|l|}{ Site of disease } \\
\hline Colon & 14 & 12 & \multirow[t]{2}{*}{0.6539} \\
\hline Rectum & 2 & 4 & \\
\hline \multicolumn{4}{|l|}{ Differentiation, $\mathrm{n}$} \\
\hline Well, moderate & 16 & 15 & \multirow[t]{2}{*}{0.9999} \\
\hline Poorly, mucinous & 0 & 1 & \\
\hline \multicolumn{4}{|l|}{ Tumor depth, $\mathrm{n}$} \\
\hline $\mathrm{T} 3$ & 15 & 11 & \multirow[t]{2}{*}{0.1719} \\
\hline $\mathrm{T} 4$ & 1 & 4 & \\
\hline \multicolumn{4}{|c|}{ Lymphatic invasion, $\mathrm{n}$} \\
\hline Positive & 10 & 5 & \multirow[t]{2}{*}{0.0679} \\
\hline Negative & 5 & 10 & \\
\hline \multicolumn{4}{|l|}{ Venous invasion, $\mathrm{n}$} \\
\hline Positive & 9 & 4 & \multirow[t]{2}{*}{0.0654} \\
\hline Negative & 6 & 11 & \\
\hline \multicolumn{4}{|l|}{ Nodal status, $\mathrm{n}$} \\
\hline N0, N1 & 10 & 14 & \multirow[t]{2}{*}{0.2200} \\
\hline $\mathrm{N} 2, \mathrm{~N} 3$ & 5 & 2 & \\
\hline \multicolumn{4}{|c|}{ Extrahepatic metastasis, $\mathrm{n}$} \\
\hline Positive & 1 & 4 & \multirow[t]{2}{*}{0.3326} \\
\hline Negative & 15 & 12 & \\
\hline \multicolumn{4}{|c|}{ Timing of hepatic metastasis, $\mathrm{n}$} \\
\hline Simultaneous & 8 & 7 & \multirow[t]{2}{*}{0.9999} \\
\hline Metachronous & 8 & 9 & \\
\hline \multicolumn{4}{|c|}{ Number of hepatic metastases, $n$} \\
\hline Single & 8 & 15 & 0.0059 \\
\hline Multiple & 8 & 1 & 0.0204 \\
\hline \multicolumn{4}{|c|}{ Size of metastasis, mm } \\
\hline Median & 31.3 & 20.6 & \multirow{3}{*}{0.0131} \\
\hline$\geq 25 \mathrm{~mm}$ & 12 & 5 & \\
\hline$<25 \mathrm{~mm}$ & 4 & 11 & \\
\hline \multicolumn{4}{|l|}{ Degree, $\mathrm{n}^{*}$} \\
\hline$\geq \mathrm{H} 1$ & 13 & 15 & \multirow[t]{2}{*}{0.5996} \\
\hline$>\mathrm{H} 2$ & 3 & 1 & \\
\hline Grade of liver meta & & & \\
\hline A & 8 & 13 & 0.0627 \\
\hline $\mathrm{B}, \mathrm{C}$ & 8 & 3 & \\
\hline
\end{tabular}

*According to Japanese Classification of Colorectal Carcinoma (14). Values shown in bold are significantly different $(p<0.05)$.

blood flow and the prediction of the antitumor effect of bevacizumab.

\section{Conclusion}

The CE ratio correlated with MVD. Although evaluation methods using the entire tumor and the tumor margin both correlated with the MVD, the CE ratio using the tumor margin was similar to MVD in its relationship with the clinicopathological factors. Taken together, these findings may suggest that the $\mathrm{CE}$ ratio using the tumor margin possibly reflects the MVD.

\section{Conflicts of Interest}

The Authors had no conflict of interest in regard to this study. No financial or material support was received for this work.

\section{Authors' Contributions}

YY, KY and MS performed the assessment of CE ratio and analyzed the relations to the clinicopathological factors. YY and KY prepared the manuscript. HY and MS supported the collection of the patient's data. HI performed immunohistochemical analysis. YN supervised all of this work.

\section{References}

1 Watanabe T, Muro K, Ajioka Y, Hashiguchi Y, Ito Y, Saito Y, Hamaguchi T, Ishida H, Ishiguro M, Ishihara S, Kanemitsu Y, Kawano H, Kinugasa Y, Kokudo N, Murofushi K, Nakajima T, Oka S, Sakai Y, Tsuji A, Uehara K, Ueno H, Yamazaki K, Yoshida M, Yoshino T, Boku N, Fujimori T, Itabashi M, Koinuma N, Morita T, Nishimura G, Sakata Y, Shimada Y, Takahashi K, Tanaka S, Tsuruta O, Yamaguchi T, Yamaguchi N, Tanaka T, Kotake K, Sugihara K; Japanese Society for Cancer of the Colon and Rectum: Japanese Society for Cancer of the Colon and Rectum (JSCCR) guidelines 2016 for the treatment of colorectal cancer. Int J Clin Oncol 23: 1-34, 2018. PMID: 28349281, DOI: 10.1007/s10147-017-1101-6.

2 Topham C and Adam R: Oncosurgery: A new reality in metastatic colorectal carcinoma. Semin Oncol 29: 3-10, 2002. PMID: 12422303, DOI: 10.1053/sonc.2002.35526.

3 Min BS, Kim NK, Ahn JB, Roh JK, Kim KS, Choi JS, Cha SH and Kim H: Cetuximab in combination with 5-fluorouracil, leucovorin and irinotecan as a neoadjuvant chemotherapy in patients with initially unresectable colorectal liver metastases. Onkologie 30: 637-643, 2007. PMID: 18063876, DOI: 10.1159/ 000109957.

4 Adam R, Aloia T, Lévi F, Wicherts DA, de Haas RJ, Paule B, Bralet MP, Bouchahda M, Machover D, Ducreux M, Castagne V, Azoulay D and Castaing D: Hepatic resection after rescue cetuximab treatment for colorectal liver metastases previously refractory to conventional systemic therapy. J Clin Oncol 25: 4593-4602, 2007. PMID: 17925554, DOI: 10.1200/ JCO.2007.10.8126.

5 Folprecht G, Gruenberger T, Bechstein W, Raab HR, Weitz J, Lordick F, Hartmann JT, Stoehlmacher-Williams J, Lang H, Trarbach T, Liersch T, Ockert D, Jaeger D, Steger U, Suedhoff T, Rentsch A and Köhne CH: Survival of patients with initially unresectable colorectal liver metastases treated with FOLFOX/ cetuximab or FOLFIRI/cetuximab in a multidisciplinary concept (CELIM study). Ann Oncol 25: 1018-1025, 2014. PMID: 24585720, DOI: 10.1093/annonc/mdu088.

6 Schwartzberg LS, Rivera F, Karthaus M, Fasola G, Canon JL, Hecht JR, Yu H, Oliner KS and Go WY: PEAK: A randomized, multicenter phase II study of panitumumab plus modified 
fluorouracil, leucovorin, and oxaliplatin (mFOLFOX6) or bevacizumab plus mFOLFOX6 in patients with previously untreated, unresectable, wild-type KRAS exon 2 metastatic colorectal cancer. J Clin Oncol 32: 2240-2247, 2014. PMID: 24687833, DOI: 10.1200/JCO.2013.53.2473.

7 Heinemann V, von Weikersthal LF, Decker T, Kiani A, VehlingKaiser U, Al-Batran SE, Heintges T, Lerchenmüller C, Kahl C, Seipelt G, Kullmann F, Stauch M, Scheithauer W, Hielscher J, Scholz M, Müller S, Link H, Niederle N, Rost A, Höffkes HG, Moehler M, Lindig RU, Modest DP, Rossius L, Kirchner T, Jung A and Stintzing S: FOLFIRI plus cetuximab versus FOLFIRI plus bevacizumab as first-line treatment for patients with metastatic colorectal cancer (FIRE-3): a randomised, open-label, phase 3 trial. Lancet Oncol 15: 1065-1075, 2014. PMID: 25088940, DOI: 10.1016/S1470-2045(14)70330-4.

8 Modest DP, Stintzing S, Fischer von Weikersthal L, Decker T, Kiani A, Vehling-Kaiser U, Al-Batran SE, Heintges T, Lerchenmüller C, Kahl C, Seipelt G, Kullmann F, Scheithauer W, Kirchner T, Jung A, Stauch M, von Einem JC, Moehler M, Held S, Heinemann V; FIRE-3 study investigators: Relation of early tumor shrinkage (ETS) observed in first-line treatment to efficacy parameters of subsequent treatment in FIRE-3 (AIOKRK0306). Int J Cancer 140: 1918-1925, 2017. PMID: 28032641, DOI: 10.1002/ijc.30592.

9 Osawa G, Yoshimatsu K, Yokomizo H, Okayama S, Sagawa M and Naritaka Y: Correlation between response to chemotherapy with concomitant bevacizumab for hepatic metastasis of colorectal cancer and degree of enhancement using contrastenhanced computed tomography. Cancer Chemother Pharmacol 72: 209-215, 2013. PMID: 23670642, DOI: 10.1007/s00280013-2186-X.

10 Takebayashi Y, Aklyama S, Yamada K, Akiba S and Aikou T: Angiogenesis as an unfavorable prognostic factor in human colorectal carcinoma. Cancer 78: 226-231, 1996. PMID: 8673996, DOI: 10.1002/(SICI)1097-0142(19960715)78:2<226: :AID-CNCR6>3.0.CO;2-J

11 Nanashima A, Shibata K, Nakayama T, Tobinaga S, Araki M, Kunizaki M, Takeshita H, Hidaka S, Sawai T, Nagayasu T and Yasutake T: Clinical significance of microvessel count in patients with metastatic liver cancer originating from colorectal carcinoma. Ann Surg Oncol 16: 2130-2137, 2009. PMID: 19495885, DOI: 10.1245/s10434-009-0459-8.

12 Pusztaszeri MP, Seelentag W and Bosman FT: Immunohistochemical expression of endothelial markers CD31, CD34, von Willebrand factor, and FLI-1 in normal human tissues. J Histochem Cytochem 54: 385-395, 2006. PMID: 16234507 , DOI: $10.1369 /$ jhc.4A6514.2005.

13 Wang D, Stockard CR, Harkins L, Harkins L, Lott P, Salih C, Yuan K, Buchsbaum D, Hashim A, Zayzafoon M, Hardy RW, Hameed O, Grizzle W and Siegal GP: Immunohistochemistry in the evaluation of neovascularization in tumor xenografts. Biotech Histochem 83: 179-189, 2008. PMID: 16234507, DOI: 10.1369/jhc.4A6514.2005.

14 Japanese Classification of Colorectal Carcinoma: Japanese Society for Cancer of the Colon and Rectum. Second Edition. Kanehara \& Co., Ltd., Tokyo 2009.

15 Bergers $\mathrm{G}$ and Benjamin LE: Tumorigenesis and the angiogenic switch. Nat Rev Cancer 3: 401-410, 2003. PMID: 12778130 , DOI: $10.1038 / \mathrm{nrc1093.}$
16 Dvorak HF: Vascular permeability factor/vascular endothelial growth factor: A critical cytokine in tumor angiogenesis and a potential target for diagnosis and therapy. J Clin Oncol 20: 43684380, 2002. PMID: 12409337, DOI: 10.1200/JCO.2002.10.088.

17 Ferrara N: Vascular endothelial growth factor: basic science and clinical progress. Endocr Rev 25: 581-611, 2004. PMID: 15294883, DOI: 10.1210/er.2003-0027.

18 Takahashi Y, Kitadai Y, Bucana CD, Cleary KR and Ellis LM: Expression of vascular endothelial growth factor and its receptor, KDR, correlates with vascularity, metastasis, and proliferation of human colon Cancer Res 55: 3964-3968, 1995. PMID: 7664263.

19 Takahashi Y, Tucker SL, Kitadai Y, Koura AN, Bucana CD, Cleary KR and Ellis LM: Vessel counts and expression of vascular endothelial growth factor as prognostic factors in nodenegative colon cancer. Arch Surg 132: 541-546, 1997. PMID: 9161399.

20 Konno H, Tanaka T, Baba M, Kanai T, Matsumoto K, Kamiya K, Nakamura S and Baba S: Quantitative analysis of vascular endothelial growth factor in colon cancer. Clinical and experimental. Eur Surg Res 30: 273-278, 1998. PMID: 9704754, DOI: $10.1159 / 000008587$.

21 Chun YS, Vauthey JN, Boonsirikamchai P, Maru DM, Kopetz S, Palavecino M, Curley SA, Abdalla EK, Kaur H, Charnsangavej $\mathrm{C}$ and Loyer EM: Association of computed tomography morphologic criteria with pathologic response and survival in patients treated with bevacizumab for colorectal liver metastases. JAMA 302: 2338-2344, 2009. PMID: 19952320, DOI: 10.1001/jama.2009.1755.

22 Konerding MA, Fait E and Gaumann A: 3D microvascular architecture of pre-cancerous lesions and invasive carcinomas of the colon. Br J Cancer 84: 1354-1362, 2001. PMID: 11355947, DOI: $10.1054 /$ bjoc.2001.1809.

23 Strohmeyer D, Strauss F, Rössing C, Roberts C, Kaufmann O, Bartsch $\mathrm{G}$ and Effert P: Expression of bFGF, VEGF and c-MET and their correlation with microvessel density and progression in prostate carcinoma. Anticancer Res 24: 1797-1804, 2004. PMID: 15274358.

24 Jiang C, Yang P, Lei J, Li J, Yan K, Li F, Yan R and Xia L: The application of iodine quantitative information obtained by dualsource dual-energy computed tomography on chemoradiotherapy effect monitoring for cervical cancer: A Preliminary Study. J Comput Assist Tomogr 41: 737-745, 2017. PMID: 28448413, DOI: $10.1097 /$ RCT.0000000000000603

25 Kawamoto S, Fuld MK, Laheru D, Huang P and Fishman EK: Assessment of iodine uptake by pancreatic cancer following chemotherapy using dual-energy CT: Abdom Radiol 43: 445456, 2018. PMID: 29473093, DOI: 10.1007/s00261-017-1338-6

26 Kim H, Goo JM, Kang CK, Chae KJ and Park CM: Comparison of iodine density measurement among dual-energy computed tomography scanners from 3 vendors. Invest Radiol 53: 321-332, 2018. PMID: 29329150. DOI: 10.1097/RLI.0000000000000446.

Received January 4, 2019

Revised January 28, 2019 Accepted February 4, 2019 